\title{
Structural Analysis of the cl-Par-4 Tumor Suppressor as a Function of Ionic Environment
}

\author{
Krishna K. Raut, Komala Ponniah and Steven M. Pascal * \\ Department of Chemistry and Biochemistry, Old Dominion University, Norfolk, VA 23529, USA; \\ kraut@odu.edu (K.K.R.); kponniah@odu.edu (K.P.) \\ * Correspondence: spascal@odu.edu; Tel.: +1-757-683-6763
}

Citation: Raut, K.K.; Ponniah, K.;

Pascal, S.M. Structural Analysis of the cl-Par-4 Tumor Suppressor as a Function of Ionic Environment. Biomolecules 2021, 11, 386. https:// doi.org/10.3390/biom11030386

Academic Editor: Simona Maria Monti

Received: 27 January 2021

Accepted: 26 February 2021

Published: 5 March 2021

Publisher's Note: MDPI stays neutral with regard to jurisdictional claims in published maps and institutional affiliations.

Copyright: (c) 2021 by the authors. Licensee MDPI, Basel, Switzerland. This article is an open access article distributed under the terms and conditions of the Creative Commons Attribution (CC BY) license (https:/ / creativecommons.org/licenses/by/ $4.0 /)$.

\begin{abstract}
Prostate apoptosis response-4 (Par-4) is a proapoptotic tumor suppressor protein that has been linked to a large number of cancers. This 38 kilodalton $(\mathrm{kDa})$ protein has been shown to be predominantly intrinsically disordered in vitro. In vivo, Par-4 is cleaved by caspase-3 at Asp-131 to generate the $25 \mathrm{kDa}$ functionally active cleaved Par-4 protein (cl-Par-4) that inhibits NF-kB-mediated cell survival pathways and causes selective apoptosis in tumor cells. Here, we have employed circular dichroism (CD) spectroscopy and dynamic light scattering (DLS) to assess the effects of various monovalent and divalent salts upon the conformation of cl-Par-4 in vitro. We have previously shown that high levels of sodium can induce the cl-Par-4 fragment to form highly compact, highly helical tetramers in vitro. Spectral characteristics suggest that most or at least much of the helical content in these tetramers are non-coiled coils. Here, we have shown that potassium produces a similar effect as was previously reported for sodium and that magnesium salts also produce a similar conformation effect, but at an approximately five times lower ionic concentration. We have also shown that anion identity has far less influence than does cation identity. The degree of helicity induced by each of these salts suggests that the "Selective for Apoptosis in Cancer cells" (SAC) domain-the region of Par-4 that is most indispensable for its apoptotic function-is likely to be helical in cl-Par-4 under the studied high salt conditions. Furthermore, we have shown that under medium-strength ionic conditions, a combination of high molecular weight aggregates and smaller particles form and that the smaller particles are also highly helical, resembling at least in secondary structure, the tetramers found at high salt.
\end{abstract}

Keywords: intrinsically disordered protein (IDP); prostate apoptosis response-4 (Par-4); tumor suppressor; circular dichroism (CD) spectroscopy; dynamic light scattering (DLS); aggregation; coiled-coil; caspase

\section{Introduction}

Prostate apoptosis response-4 (Par-4) is a tumor suppressor protein that is capable of selectively inducing apoptosis in cancer cells while leaving healthy cells unaffected [1]. Par-4 was first identified through its down-regulation in therapy-resistant prostate cancer cells and has since been shown to be ubiquitously expressed, localized in the cytoplasm, the nucleus and extracellularly, and linked to a variety of cancers [2-5]. The par-4 gene maps to human chromosome 12q21 and encodes an approximately 40 kilodalton (kDa) protein of 340 amino acids [6]. While Par-4 has been shown to be largely intrinsically disordered in vitro, it does contain several identifiable domains and features. The first identified domain was the C-terminal coiled-coil, which is highly conserved across humans, mice, and rats [7]. This region contains a small nuclear export signal (NES). The coiled-coil is responsible for Par-4 dimerization, and for most known interactions with cellular proteins. Two nuclear localization signals are found in the N-terminal half of the protein, though only the 2nd, NLS2, has been shown to affect localization [8,9]. Par-4 also contains a unique and highly conserved "Selective for Apoptosis in Cancer cells" (SAC) domain, which is the minimal region required to induce apoptosis [8,9]. 
Although Par-4 is expressed in both normal and cancer cells, only cancer cells are typically susceptible to the killing effect of this protein. The two best-documented factors controlling this selectivity are (i) GRP78 levels and (ii) PKA levels. (i) Extra-cellular Par4 can enter cancer cells by binding to the surface receptor GRP78 via the Par-4 SAC domain [10]. GRP78 levels in healthy cells are typically very low or even undetectable, abrogating entry of extracellular Par-4 into healthy cells. (ii) Protein Kinase A (PKA) is required to phosphorylate intracellular Par-4 at residue T163, which is within the SAC domain $[4,11,12]$. This phosphorylation event leads to the inhibition of PKC- $\zeta$ by Par- 4 , which in turn suppresses phosphorylation of FADD by PKC- $\zeta$. Unphosphorylated FADD is required for DISC (Death-Inducing Signal Complex) formation at the plasma membrane, which triggers the caspase-8-mediated apoptotic pathway $[9,10]$. As with GRP78, the basal level of PKA in healthy cells is typically low and insufficient to cause phosphorylation of Par-4, thereby preventing DISC formation in healthy cells.

Interestingly, one key event downstream of caspase-8 activation is the activation of caspase-3, which in turn cleaves intracellular Par-4. Caspase-3 cleaves Par-4 after D131, producing two fragments: a $15 \mathrm{kDa}$ amino-terminal fragment (called PAF for Par-4 Amino terminal Fragment) and a $25 \mathrm{kDa}$ carboxy-terminal fragment (called cl-Par-4 for cleaved) $[8,13]$. Assisted by NLS2, cl-Par-4 translocates to the nucleus, where it blocks cell survival pathways by inhibiting transcriptional regulators such as NF-KB [14,15].

Intrinsically disordered proteins (IDPs) or intrinsically disordered protein regions (IDPRs) possess specific features such as a high percentage of charged residues and a low percentage of hydrophobic amino acids [16-18]. These exceptional characteristics lead to a disordered conformation under typical physiological conditions [19]. A number of environmental factors can, however, influence the folding of these proteins including temperature, $\mathrm{pH}$, ionic strength, post-translational modification including both phosphorylation and targeted cleavage by proteases, and interaction with natural ligands or protein partners $[16,20,21]$. Significant evidence has arisen showing enhanced folding of IDPs with increased ion concentration and ionic charge density, though unfolding can also be triggered by the same factors [22].

We have previously shown that high levels of sodium chloride or acidic $\mathrm{pH}$ can induce the cl-Par-4 fragment to form highly compact, highly helical structures in vitro, at high micromolar protein concentrations [23,24]. The ionic conditions required to favor these small, well-folded particles are outside of the range of conditions normally found in cells. This led to the hypothesis that multiple factors, including multiple ion types, may combine forces to influence Par- 4 conformation. To begin to test this hypothesis, we here have examined and compared the structural characteristics of cl-Par-4 as a function of sodium chloride, potassium chloride, magnesium chloride, and magnesium sulfate concentration. The results shed light on the role of cations versus anions, their charge densities, and also on the role of the caspase-induced cleavage event that produces cl-Par-4, in influencing Par-4 structure, and subsequently, Par-4 localization and function.

\section{Materials and Methods}

\subsection{Expression and Purification of cl-Par-4}

BL21 (DE3) Escherichia coli cells transfected with a codon-optimized construct of clPar-4 in the modified expression vector H-MBP-3C [25] were grown in Luria-Bertani (LB) media with $100 \mu \mathrm{g} / \mathrm{mL}$ ampicillin at $37^{\circ} \mathrm{C}$ until an $\mathrm{OD}_{600}$ of $0.8-0.9$ was reached. The cells were then induced for protein expression with the addition of $0.5 \mathrm{mM}$ isopropyl thio- $\beta$-Dgalactoside (IPTG) and grown at $15^{\circ} \mathrm{C}$ until $\mathrm{OD}_{600}$ reached 1.5-1.6. The harvested cells were lysed by a combination of mechanical (sonication) and enzymatic (lysozyme) methods and extracted protein was purified with immobilized metal affinity chromatography (IMAC) using a HisTrap HP 5 mL column (GE Healthcare, Uppsala, Sweden). The His-MBP tag was cleaved from cl-Par-4 by treating the protein with the His-tagged 3C-protease enzyme. The purified protein was then further dialyzed against the storage buffer $(10 \mathrm{mM}$ Tris, $1 \mathrm{M} \mathrm{NaCl}, 1 \mathrm{mM}$ TCEP, $\mathrm{pH}$ 7.0) and concentrated by centrifugation using a $10 \mathrm{kDa}$ MWCO 
Vivaspin Turbo 15 (Sartorius, Epsom, UK). The protein concentration was determined by taking absorbance readings at $280 \mathrm{~nm}$ using a BioDrop DUO (BioDrop Ltd., Cambridge, UK) and the theoretical extinction coefficient of $6400 \mathrm{M}^{-1} \mathrm{~cm}^{-1}$. The protein was finally lyophilized using a FreeZone Freeze Dryer (LABCONCO Corporation, Kansas City, MO, USA), stored at $-80{ }^{\circ} \mathrm{C}$, and re-solubilized in sterile distilled water when required. In our experience, in vitro CD and DLS data obtained with cl-Par-4 samples prepared, lyophilized, and redissolved as described above were indistinguishable from data obtained with fresh (never lyophilized) samples.

\subsection{Circular Dichroism Spectroscopy}

Circular dichroism (CD) spectra of the protein were obtained on a J-815 CD spectrometer (Jasco, Easton, MD, USA). The cl-Par-4 samples were at a concentration of $0.2 \mathrm{mg} / \mathrm{mL}$ in Tris-HCl buffer (10 mM Tris, $1 \mathrm{mM} \mathrm{DTT}$, $\mathrm{pH}$ 7.0) with varying concentrations of monovalent and divalent cations present (10-1000 mM). Each cl-Par-4 sample used for CD spectroscopy contained $40 \mathrm{mM} \mathrm{NaCl}$ as a residual due to the dilution from the storage buffer $(10 \mathrm{mM}$ Tris, $1 \mathrm{mM}$ TCEP, and $1 \mathrm{M} \mathrm{NaCl}$, $\mathrm{pH}$ 7.0). For the filtered samples, sample preparation was identical except for the filtration of the sample through a 0.45-micron Nalgene SFCA membrane syringe filter (Thermo Fisher Scientific, Rochester, NY, USA) immediately prior to $\mathrm{CD}$ spectroscopy. For the centrifuged samples, sample preparation was identical except that samples were centrifuged for $5 \mathrm{~min}$ at 10,000 RPM $(9615 \times g)$ using a Sorvall Legend Micro 21R Centrifuge (Thermo Fisher Scientific, Germany), and the supernatant was used for the CD spectroscopy. CD data were recorded over a 400-190 $\mathrm{nm}$ wavelength range at a scan speed of $20 \mathrm{~nm} / \mathrm{min}$ using a $1 \mathrm{~mm}$ pathlength quartz cuvettes at $25^{\circ} \mathrm{C}$. A buffer blank was subtracted from the spectra, which were then smoothed using a means-movement function of $25 \mathrm{~nm}$ and converted to molar ellipticity The deconvolution of CD spectra for estimation of secondary structure content was done using the SELCON3 algorithm through the DichroWeb server [26].

\subsection{Dynamic Light Scattering}

Dynamic light scattering (DLS) data were recorded using a NanoBrook Omni particle sizer and zeta potential analyzer (Brookhaven Instruments Corporation, Holtsville, NY, USA). Protein samples were at a concentration of $0.2 \mathrm{mg} / \mathrm{mL}$ in Tris buffer $(10 \mathrm{mM}$ Tris, $1 \mathrm{mM}$ DTT, $\mathrm{pH}$ 7.0) with varying concentrations of monovalent and divalent cations (10-1000 mM). Filtered and centrifuged samples were prepared as described above. The data were recorded at $25^{\circ} \mathrm{C}$ using a standard diode laser at $640 \mathrm{~nm}$ wavelength, scattering angle of $173^{\circ}$, and plastic cuvettes of $1 \mathrm{~cm}$ pathlength. Five scans were recorded for each sample and hydrodynamic radii (Stokes' radii) were calculated from the mean effective diameter obtained from the summary statistical report of the NanoBrook software.

\subsection{SDS-PAGE}

Sodium dodecyl sulfate-polyacrylamide gel electrophoresis (SDS-PAGE) gels of 4-12\% were prepared using a gel casting system (Bio-Rad Laboratories, Inc., Irvine, CA, USA). Filtered samples were prepared as mentioned above. The samples, each containing initially $0.2 \mathrm{mg} / \mathrm{mL}$ of the protein (filtered samples contained less protein), were prepared for loading by combining $16 \mu \mathrm{L}$ of each sample with $4 \mu \mathrm{L}$ of $5 \times$ sample loading dye, mixed well, and heated at $90^{\circ} \mathrm{C}$ for $2 \mathrm{~min}$. Next, $20 \mu \mathrm{L}$ of each sample was loaded into separate wells in the gel. The gels were run in $1 \times$ SDS-PAGE buffer (Tris base, glycine, SDS, and water) using the PowerPac Basic device (Bio-Rad Laboratories, Inc., Irvine, CA, USA) for $20 \mathrm{~min}$ with a low voltage of $50 \mathrm{~V}$ and then $60 \mathrm{~min}$ with a high voltage of $150 \mathrm{~V}$. The gels were then stained for $5 \mathrm{~h}$ in Coomassie stain $(0.2 \% \mathrm{R}-250,7.5 \%$ acetic acid, $50 \%$ ethanol and water) and de-stained overnight in de-staining solution (7.5\% acetic acid, $50 \%$ ethanol, and water). Visualization of the gel was done on a white lightbox. 


\section{Results}

\subsection{Disorder Prediction in cl-Par-4}

The cl-Par-4 fragment is the functionally active fragment of the Par-4 protein that enters the nucleus. This region of the protein can be further subdivided as follows: (Figure 1a): the SAC (Selective for Apoptosis induction in Cancer cells) domain, the CC (Coiled-Coil) domain, and the Linker between these two domains. In addition, the SAC domain contains an NLS (Nuclear Localization Signal) near its N-terminus, and the CC domain contains an LZ (Leucine Zipper) domain which comprises its C-terminal half [23]. Prediction of disorder in these domains was done by using DISOPRED3, which utilizes X-ray diffraction databases (Figure 1b) $[27,28]$. Considering a probability of 0.5 (dashed line) as the demarcation line, the analysis clearly predicts order in the CC domain and disorder in the Linker, while the SAC domain has intermediate character, approaching the order/disorder line. Previous sequence analysis also showed mixed order/disorder propensity and some helical character in the SAC domain, and so order in the SAC domain would not be surprising, under the right conditions [23].

a

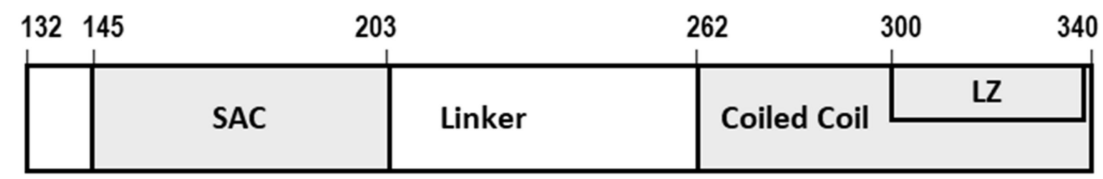

b

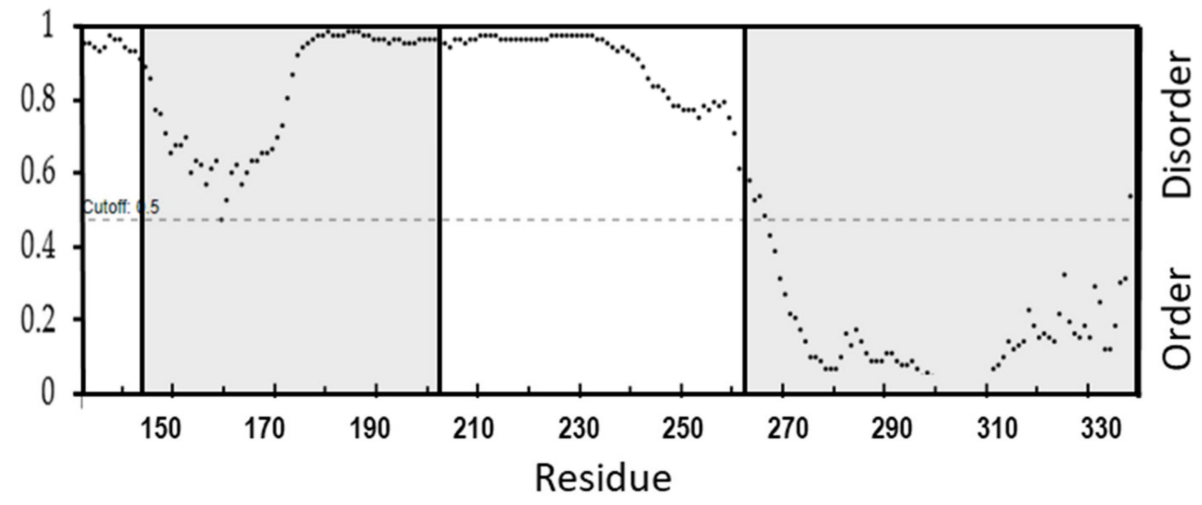

Figure 1. (a) Schematic diagram showing domains of cleaved Par-4 protein (cl-Par-4) and (b) Disorder prediction in cl-Par-4 using DISOPRED3.

\subsection{Differential Effect of Monovalent \& Divalent Ions on the Structure of cl-Par-4}

We have previously shown that at a high $\mathrm{NaCl}$ concentration, cl-Par-4 forms a highly helical tetramer with mostly non-coiled coil helices [24]. Here, we investigated the effects of high levels of a different monovalent cation (potassium), with a different size and charge density. The relative effects of $\mathrm{NaCl}$ and $\mathrm{KCl}$ on $\mathrm{CD}$ spectra of cl-Par-4 are shown in Figure 2a. All cl-Par-4 samples were at a concentration of $0.2 \mathrm{mg} / \mathrm{mL}$ in Tris-buffer of $\mathrm{pH} 7.0$ containing various concentrations of either $\mathrm{NaCl}$ or $\mathrm{KCl}$.

At a $500 \mathrm{mM}$ salt concentration, CD spectra were characteristic of $\alpha$-helical content with intense dichroism minima at $222 \mathrm{~nm}$ and $208 \mathrm{~nm}$ [29,30]. At lower salt concentrations, the intensity of the CD spectra was reduced, which will be discussed further in Section 3.4. At all concentrations, the effect of Na vs. K cations appeared to be similar.

For isolated alpha-helices, an intensity ratio of greater than 1 for the two minima at $\theta_{222}$ and $\theta_{208}$ indicates coiled-coil formation [24,29,31]. By these criteria, it appears that the $500 \mathrm{mM}$ salt sample did not form a significant coiled-coil, but that the lower salt samples may. An alternative interpretation of conformation at low and medium salt concentrations is presented in the discussion section.

The effects of the divalent cation magnesium on the structural conformation of cl-Par-4 were also investigated via $\mathrm{CD}$ spectroscopy. Sample preparation was similar to above, but with various concentrations of $\mathrm{MgSO}_{4}$ instead of $\mathrm{NaCl}$ or $\mathrm{KCl}$. CD spectra (Figure 2b) 
showed a similar trend as obtained with monovalent cations, with higher intensity at higher salt concentration. Again, the $\theta_{222}: \theta_{208}$ ratio suggests little coiled-coil formation at high salt concentration and the possibility of coiled-coil at low salt concentration.

However, the most striking difference between monovalent and divalent cation salt samples was in the concentrations of demarcation: all samples with $75 \mathrm{mM}$ and higher $\mathrm{MgSO}_{4}$ showed similar, intense, highly helical but non-coiled coil CD spectra, whereas only the $500 \mathrm{mM}$ monovalent salt samples produced such a result. Intermediate spectra occurred for $50 \mathrm{mM} \mathrm{MgSO}_{4}$, while analogous intermediate spectra occurred at a much higher monovalent salt concentration of $250 \mathrm{mM} \mathrm{NaCl}$ or $\mathrm{KCl}$. The effects of $\mathrm{MgSO}_{4}$ and $\mathrm{KCl}$ are directly compared in Figure 2c. These results suggest that the divalent magnesium cation is five or more times as effective as monovalent cations in influencing the structure of cl-Par-4.

Next, the effect of monovalent versus divalent anions on the structure of cl-Par-4 was investigated by comparing samples prepared with $\mathrm{MgSO}_{4}$ versus $\mathrm{MgCl}_{2}$. The results showed little difference between like concentrations of $\mathrm{MgSO}_{4}$ and $\mathrm{MgCl}_{2}$ (Figure 2d), suggesting that cation identity exerts a far greater influence on cl-Par-4 structure than does anion identity.
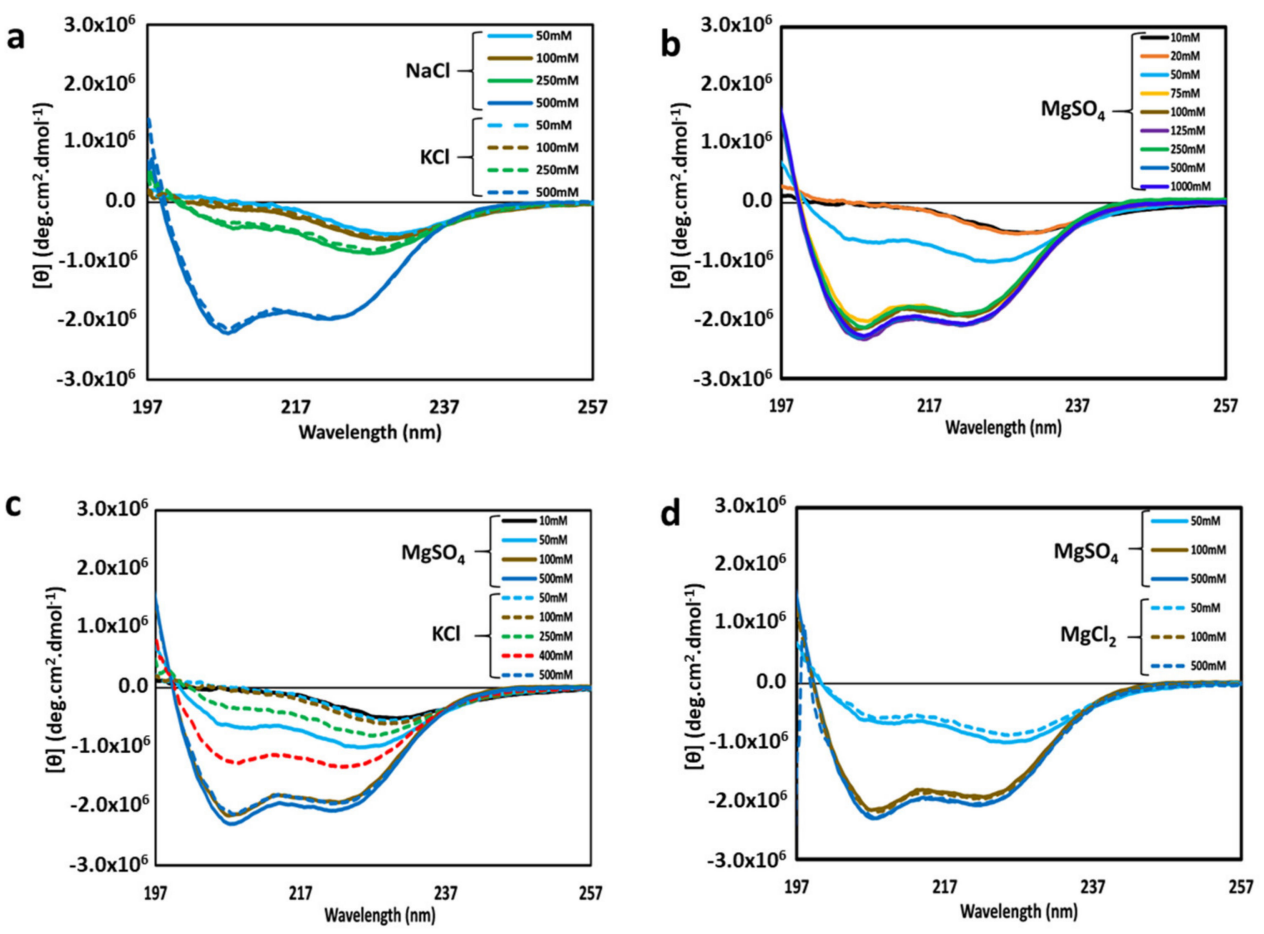

Figure 2. Overlay of circular dichroism (CD) spectra of cl-Par-4 at various concentrations of the following salts: (a) $\mathrm{NaCl}$ (solid lines) and $\mathrm{KCl}$ (dashed lines); (b) $\mathrm{MgSO}_{4}$; (c) $\mathrm{MgSO}_{4}$ (solid lines) and $\mathrm{KCl}$ (dashed lines); (d) $\mathrm{MgSO}_{4}$ (solid lines) and $\mathrm{MgCl}_{2}$ (dashed lines). The salt concentrations are indicated by the color legend within each panel. All spectra were recorded at $\mathrm{pH}$ 7.0.

\subsection{Effect of Monovalent $\mathcal{E}$ Divalent Ions on Hydrodynamic Size of cl-Par-4}

The size of protein molecules in solution (hydrodynamic size) provides information about conformation. Small size indicates a compact and well-folded conformation whereas large size indicates a highly self-associated, or aggregated conformation, that may or may not also be significantly disordered. The hydrodynamic size distribution of cl-Par-4 was investigated using dynamic light scattering (DLS). Sample preparation was similar to above, but with the following concentrations of $\mathrm{NaCl}: 50,100,250$, and $500 \mathrm{mM}$ or $\mathrm{MgSO}_{4}: 10,50$, 100 , and $500 \mathrm{mM}$. The result showed relatively small particles (Stokes' radius, Rs $\approx 200 \mathrm{~nm}$ ) in the sample with $500 \mathrm{mM}$ of $\mathrm{NaCl}$ (Figure 3a). The observed hydrodynamic sizes were significantly larger $(\mathrm{Rs} \approx 1000 \mathrm{~nm})$ at the three lower $\mathrm{NaCl}$ concentrations $(50,100$, and 
$250 \mathrm{mM}$ ), indicating the presence of large aggregates. The polydispersity values associated with DLS measurements (see numbers above bars in Figure 3a) correlate strongly with Stokes' radii, indicating that in general, samples with larger particles also contain a broader range of particle sizes.

A similar trend of smaller particle size at higher salt was observed in the presence of $\mathrm{MgSO}_{4}$ (Figure 3b). However, the transition between small (Rs $\approx 200 \mathrm{~nm}$ ) and large $(\mathrm{Rs} \approx 1000 \mathrm{~nm})$ particles apparently occurs somewhere between $\mathrm{MgSO}_{4}$ concentrations of $50 \mathrm{mM}$ and $100 \mathrm{mM}$, suggesting that the divalent magnesium ion is approximately five times more potent than the monovalent cation in influencing cl-Par-4 particle size. Again, the largest Stokes' radii (at $10 \mathrm{mM} \mathrm{MgSO}_{4}$ ) were associated with the broadest range of particle sizes, as shown by polydispersity measurements in Figure 3b. However, in general, less polydispersity was seen in the $\mathrm{MgSO}_{4}$ samples than in the $\mathrm{NaCl}$ samples, indicating that even when large particles were present, magnesium induced a more uniform particle size than did sodium.

Note that large particle size as detected by DLS (Figure 3a,b) corresponded closely with reduced CD intensity (Figure 2a,b). However, the correspondence was not perfect. In particular, note that DLS detected similar particle sizes at 50, 100, and $250 \mathrm{mM} \mathrm{NaCl}$ (Figure 3a), but that $250 \mathrm{mM}$ monovalent salt produced a significantly higher dichroism intensity than 50 or $100 \mathrm{mM}$ had (Figure 2a). The $\mathrm{MgSO}_{4}$ data was more self-consistent, but still not perfectly so, particularly at $50 \mathrm{mM}$ (see Figures $2 \mathrm{~b}$ and $3 \mathrm{~b}$ ). This inconsistency with the intermediate concentrations of both monovalent and divalent cations could be due to the fact that scattering is highly sensitive to the largest particles in solution. The result was consistent with the concept that the largest particles were as shown in Figure $3 a, b$, but that more of these large particles form at lower salt concentrations, which resulted in more CD signal loss, possibly due at least in part to a smaller effective cross-section being available for CD measurements [32].

a

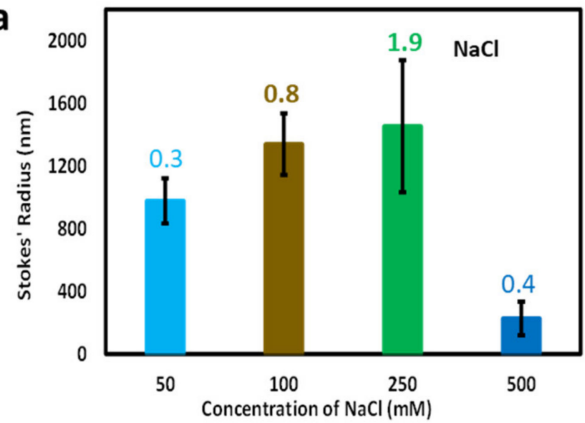

C

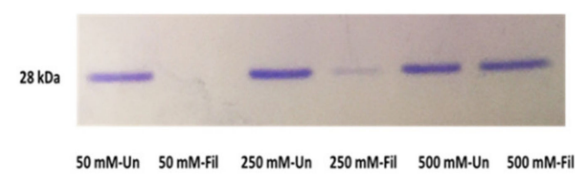

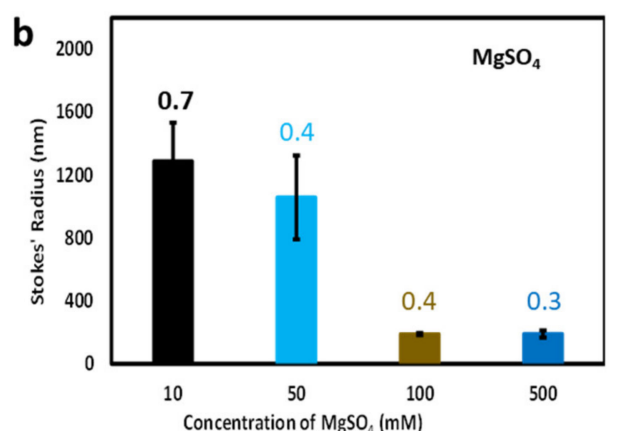

d

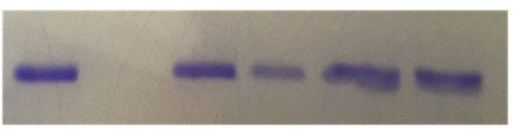

$10 \mathrm{mM}$-Un $10 \mathrm{mM}$-Fil $50 \mathrm{mM}$-Un $50 \mathrm{mM}$-Fil $500 \mathrm{mM}$-Un $500 \mathrm{mM}$-Fil

Figure 3. Particle size analysis of cl-Par-4 as a function of salt concentration. (a) dynamic light scattering (DLS)-derived Stokes' radii vs. $\mathrm{NaCl}$ concentration. (b) DLS-derived Stokes' radii vs. $\mathrm{MgSO}_{4}$ concentration. (c) SDS-PAGE analysis of samples from panel (a), before and after filtration. (d) SDS-PAGE analysis of samples from panel (b), before and after filtration. In panels (a) and (b), error bars represent the standard deviation in Stokes' radii from multiple runs, and the number above each bar represents the average polydispersity value for these runs.

Sample filtration was next used to further analyze the relationship between CD spectroscopy and particle size. The fraction of protein removed by filtration was analyzed via SDS-PAGE. For this analysis, $0.2 \mathrm{mg} / \mathrm{mL}$ cl-Par- 4 samples with low salt $(50 \mathrm{mM} \mathrm{NaCl}$ or $\left.10 \mathrm{mM} \mathrm{MgSO}_{4}\right)$, intermediate salt $\left(250 \mathrm{mM} \mathrm{NaCl}\right.$ or $\left.50 \mathrm{mM} \mathrm{MgSO}_{4}\right)$, and high salt (500 mM $\mathrm{NaCl}$ or $500 \mathrm{mM} \mathrm{MgSO}_{4}$ ) were used. Corresponding filtered samples were prepared by 
passing the samples through 0.45-micron filters. The results for $\mathrm{NaCl}$ and $\mathrm{MgSO}_{4}$ samples are shown in Figure 3c,d, respectively. Each of the unfiltered samples showed similar gel band intensity. After filtration, the bands for low salt samples essentially disappeared, the bands for medium salt samplers were reduced, and the bands for high salt samples remained nearly as intense as before filtration. These results are consistent with the concept that high salt prevents large particle sizes, low salt samples consist almost entirely of large particles, and intermediate salt produces a mixture of large and small particles. In fact, Figure 3a seems to indicate that intermediate $\mathrm{NaCl}$ concentration produces a small number of very large particles, that are larger than the largest particles formed at low salt. One possible explanation for this observation is a sort of slow growth model: in low salt, the protein may quickly coalesce principally into $1000 \mathrm{~nm}$ aggregates that do not aggregate further, while the aggregates that form at medium salt are surrounded by additional smaller particles that can continue to be adsorbed by the aggregated particles, ultimately producing larger particles than seen at low salt. This continuous process would be consistent with the very high polydispersity observed for the $250 \mathrm{mM} \mathrm{NaCl}$ sample.

\subsection{Effect of Filtration on DLS Measurements, CD Spectroscopy, and Secondary Structure Analysis}

To further explore the relationship between particle size and CD spectroscopy, filtered samples with low, medium, and high divalent cation concentrations $(10,50$, and $500 \mathrm{mM}$ $\mathrm{MgSO}_{4}$ ) were analyzed via DLS and CD spectroscopy. As expected, the hydrodynamic sizes derived from DLS measurements (Figure 4a) indicated smaller particle sizes relative to unfiltered samples (Figure 3b), except for the high salt $500 \mathrm{mM}$ sample which predictably showed little change in particle size upon filtration. However, the filtered intermediate sample ( $50 \mathrm{mM} \mathrm{MgSO}_{4}$ ) produced the largest Stokes' radius. This pattern for the filtered $\mathrm{MgSO}_{4}$ samples (Figure 4a) now resembles the pattern observed for the unfiltered $\mathrm{NaCl}$ samples (Figure 3a), with intermediate salt producing the largest particles, possibly due to a similar slow growth mechanism as was discussed in the previous section. Bear in mind, however, that very few particles of any sort survive filtration at low salt concentration.

$\mathrm{CD}$ spectra of the filtered samples are shown in Figure $4 \mathrm{~b}$. The filtered low $\mathrm{MgSO}_{4}$ sample predictably produced almost no dichroism, since the sample concentration after filtration was extremely low. As expected, the high $\mathrm{MgSO}_{4}$ sample produced a $\mathrm{CD}$ spectrum nearly matching the pre-filtered $\mathrm{CD}$ spectrum of Figure $2 \mathrm{~b}$. The most interesting result was that for medium $\mathrm{MgSO}_{4}(50 \mathrm{mM})$. Though the intensity was low relative to the filtered high salt sample, the shape nearly matches that of the high salt sample. This suggests that, although fewer particles were present in the filtered medium $\mathrm{MgSO}_{4}$ sample (see Figure 3d), and these particles were of relatively large size (see Figure 4a), the secondary structure was very similar to that of the particles present in high salt conditions. Thus, the difference in particle size found in the filtered medium and high salt samples does not correspond to a significant change in secondary structure. Apparently, cl-Par-4 particles can self-associate without a large change in secondary structure. However, this analysis only applies to particles small enough to survive filtration. Unfiltered samples with very large particles do produce differently shaped CD spectra (Figure $2 b$, low and medium salt samples).

Secondary structure analysis was performed via deconvolution of the CD spectra using the SELCON3 algorithm [26]. Deconvolution of unfiltered and filtered $50 \mathrm{mM}$ and $500 \mathrm{mM}$ $\mathrm{MgSO}_{4}$ spectra are shown in Figure $4 \mathrm{c}, \mathrm{d}$, respectively. The deconvolution program was unable to distinguish secondary structure differences between high and medium $\mathrm{MgSO}_{4}$ samples, before and after filtration: in each of these four cases, deconvolution suggests approximately $80 \%$ helix, $15 \%$ disorder, and $5 \%$ beta turn. Deconvolution of the unfiltered $10 \mathrm{mM}$ salt CD spectrum suggested approximately $55 \%$ helix, and corresponding increases in the percentage of beta sheet, beta turn, and disorder. However, scattering by the large particles present in this sample would be expected to interfere with CD spectroscopy and hence with spectral deconvolution, and therefore the $10 \mathrm{mM} \mathrm{MgSO}_{4}$ secondary structure deconvolution is not presented in Figure 4c [33]. Deconvolution of the filtered low salt CD 
data was not possible due to lack of sufficient sample surviving filtration (see Figure $4 b$ ) and thus filtered low salt secondary structure is not presented in Figure 4d.

Both the filtered medium and high salt samples produce $C D$ spectra with a $\theta_{222}: \theta_{208}$ ratio less than one. This was consistent with the presence of mostly non-coiled coil helices in both cases. Note that before filtration, the medium salt sample produced CD spectra with a $\theta_{222}: \theta_{208}$ ratio greater than one. This result suggests that the large aggregates present in the mixed-size environment of the unfiltered medium salt sample are responsible for the shifting of the $\theta_{222}: \theta_{208}$ ratio, and that particles small enough to survive filtration contain mostly non-coiled coil helices.

a

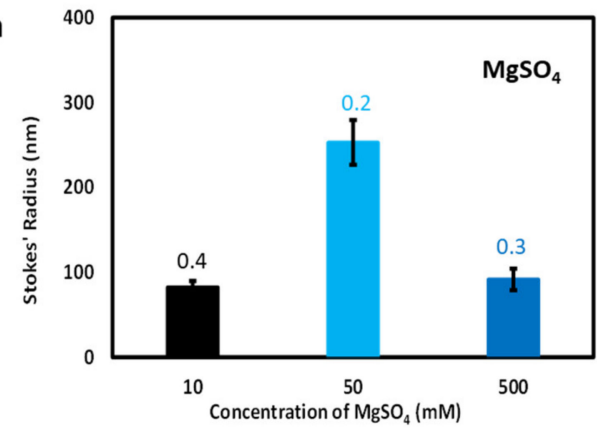

C

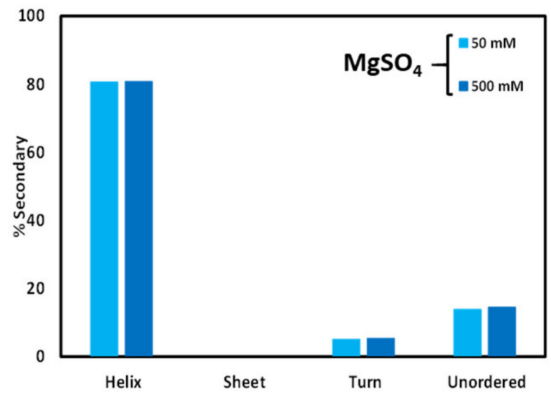

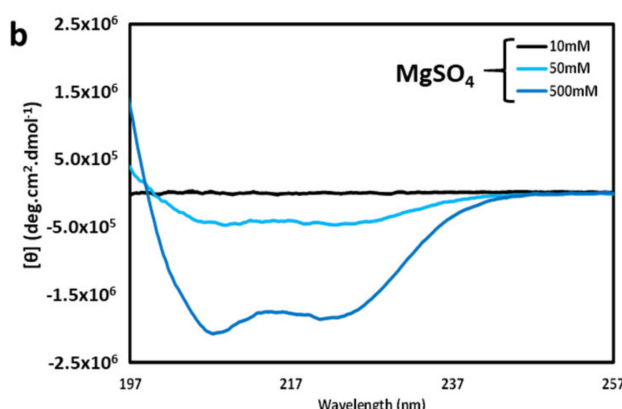

d

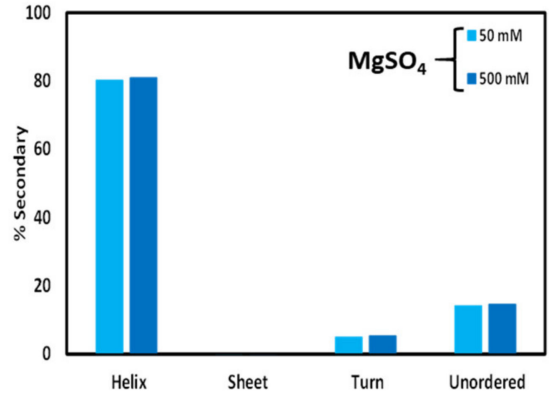

Figure 4. Effect of filtration on cl-Par-4 samples as a function of $\mathrm{MgSO}_{4}$ concentration. (a) DLSderived Stokes' radii after filtering. Error bars represent the standard deviation in Stokes' radii from multiple runs, and the number above each bar represents the average polydispersity value for these runs. (b) CD spectra after filtration. (c) Secondary structure analysis via deconvolution of CD spectra from Figure 2b [unfiltered samples]. (d) Secondary structure analysis via deconvolution of CD spectra from Figure $4 b$ [filtered samples]. Secondary structure analysis of unfiltered and filtered $10 \mathrm{mM}$ $\mathrm{MgSO}_{4}$ samples was not possible due to the presence of large particles and low protein concentration, respectively.

\subsection{Effect of Centrifugation and Reintroduction of Salt}

To corroborate the results obtained from filtration, parallel experiments were performed by centrifuging the unfiltered samples and collecting the supernatant for $C D$ analysis. CD spectra obtained from centrifuge supernatant samples are shown in Figure 5a. By comparison to the data of Figure $4 \mathrm{~b}$, it can be seen that filtration and centrifugation produced a similar effect of removing large aggregates, leaving smaller, highly helical particles in solution, although fewer particles survived filtration in the case of centrifugation. DLS analysis of the centrifuged samples used for the CD spectra in Figure 5a is shown in Figure 5b. The Stokes' radii of each of the centrifuged samples confirm that only relatively small particles survive centrifugation.

Also, to investigate the reversibility of large particle formation by cl-Par- $4,90 \mathrm{MgSO}_{4}$ was added to low salt $\left(10 \mathrm{mM} \mathrm{MgSO}_{4}\right)$ samples. $\mathrm{CD}$ analysis showed that the resulting $100 \mathrm{mM} \mathrm{MgSO}_{4}$ spectrum becomes nearly identical to the original $100 \mathrm{mM} \mathrm{MgSO}_{4}$ sample which had never been at low salt (Figure 6a). Filtering of the resulting sample caused a 
small reduction in $\mathrm{CD}$ intensity, indicating the presence of a small number of large particles before filtration.

a

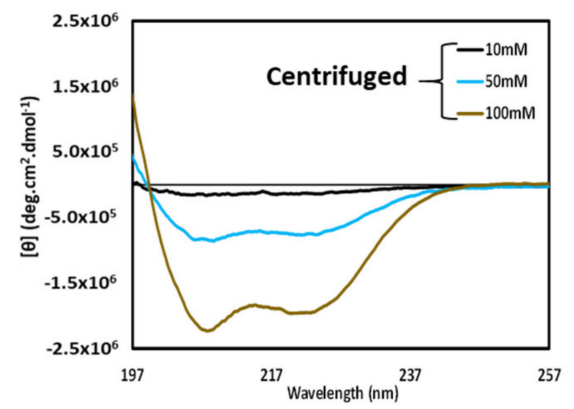

b

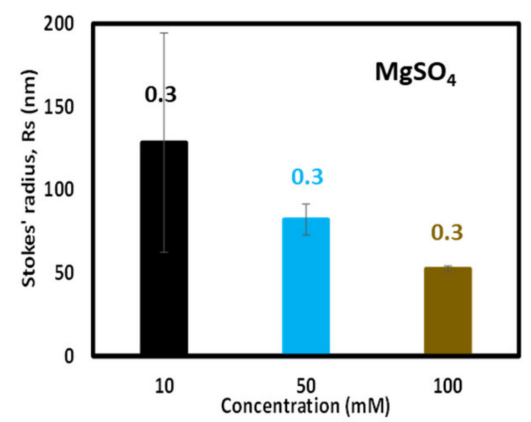

Figure 5. CD spectra and DLS analysis after centrifugation. (a) Overlay of CD spectra of supernatant after centrifugation of cl-Par-4 at various concentrations of $\mathrm{MgSO}_{4}$. The salt concentrations are indicated by the color legend within the panel. (b) Corresponding DLS of samples from panel (a). Error bars represent the standard deviation in Stokes' radii from multiple runs, and the number above each bar represents the average polydispersity value for these runs.

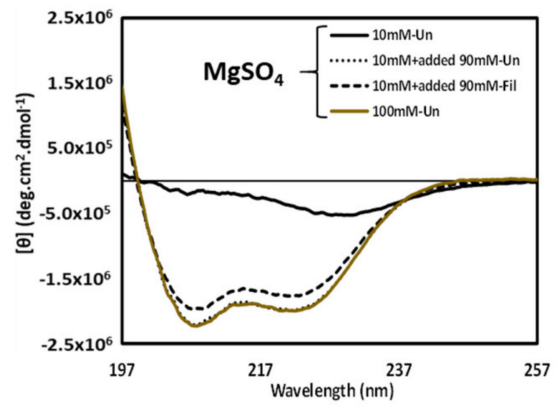

b

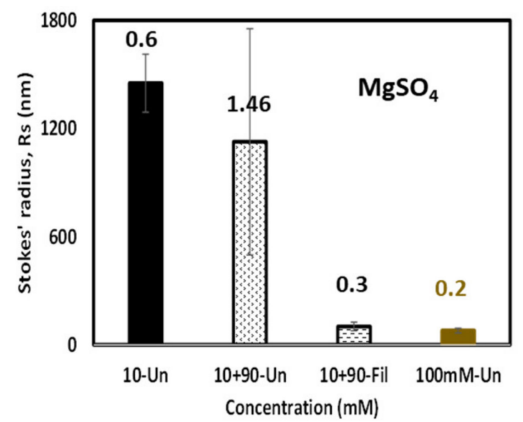

Figure 6. CD spectra and DLS analysis after reintroduction of salt. (a) $10 \mathrm{mM} \mathrm{MgSO}_{4}$ sample (solid black line) shows signs of large species formation (loss of signal); This signal loss can be eliminated by increasing the $\mathrm{MgSO}_{4}$ concentration to $100 \mathrm{mM}$ (dotted black line); the resulting spectrum overlaps nearly perfectly with that of the original $100 \mathrm{mM}$ sample (solid brown line). The dashed black line represents the slightly reduced $\mathrm{CD}$ spectrum of the added $\mathrm{MgSO}_{4}$ sample after filtration to remove any remaining large particles. (b) Corresponding DLS of samples from panel (a). Error bars represent the standard deviation in Stokes' radii from multiple runs, and the number above each bar represents the average polydispersity value for these runs.

DLS analysis of the samples from Figure 6a is shown in Figure 6b. From left to right, the large detected Stokes' radius at $10 \mathrm{mM} \mathrm{MgSO}_{4}$ appeared to become slightly smaller once $90 \mathrm{mM} \mathrm{MgSO}_{4}$ was added, but the large error bar and high polydispersity indicated a wide range of particle size. After filtration, the Stokes' radius was much smaller, approaching that of the sample that had never been at low salt. The fact that filtration had a much larger effect on the DLS result than on the CD result indicates that the reconstituted $100 \mathrm{mM}$ $\mathrm{MgSO}_{4}$ sample contained a small number of large particles that dominate the scattering. Removal of the large particles by filtration revealed that most particles were small under these conditions.

\subsection{Time-Dependent Characteristics of cl-Par-4 Samples}

To further explore the possibility of dynamic equilibrium, time course CD spectroscopy experiments (Figure 7) were performed with samples at an intermediate salt concentration $\left(50 \mathrm{mM} \mathrm{MgSO}_{4}\right)$. The spectra in Figure 7a,b were performed with a sample that had been filtered on day 1 . The shape of the CD spectra of the filtered sample changed relatively little over a seven-day period (see Figure 7a), suggesting that the sample does not rapidly 
aggregate over time. However, there is some loss of intensity, suggesting either sample loss or the formation of a small number of aggregates. DLS results showed that particle sizes remained relatively small over the time course (Figure $7 \mathrm{~b}$ ), thus indicating that loss of $\mathrm{CD}$ intensity was most likely due primarily to sample loss.

The change in the unfiltered $50 \mathrm{mM} \mathrm{MgSO}_{4}$ sample with time was more pronounced. The CD spectrum (Figure 7c) changed shape to resemble the filtered sample by day 3 . This suggests that large particles may be lost from the unfiltered sample relatively quickly, either due to dispersion into smaller particles or via settling or adhering to the sample container. Since the intensity did not increase with time, the latter mechanism of removal by settling/adherence appeared dominant, but both mechanisms may be in play. DLS results (Figure $7 \mathrm{~d}$ ) showed a significant increase in measured Stokes' radius and dispersity until day 5 , and then a reduction in size and dispersity on day 7 . The maximum particle size, to which DLS is sensitive, remained relatively large throughout the time course, indicating that aggregates were present throughout. However, since the CD spectra (Figure 7c) converted over time to a shape consistent with that displayed by smaller helical particles, the combined results seems to indicate that a small number of large particles remain over time, sufficient to influence the DLS results, but not sufficient to affect the CD spectra. The overarching result is that unfiltered, filtered, and centrifuged samples converge overtime to produce similarly shaped CD spectra indicative of highly helical particles. Taken together, these data are consistent with the presence of a dynamic equilibrium between small and large particles, which readjusts the following filtration, and is affected by settling/adherence.
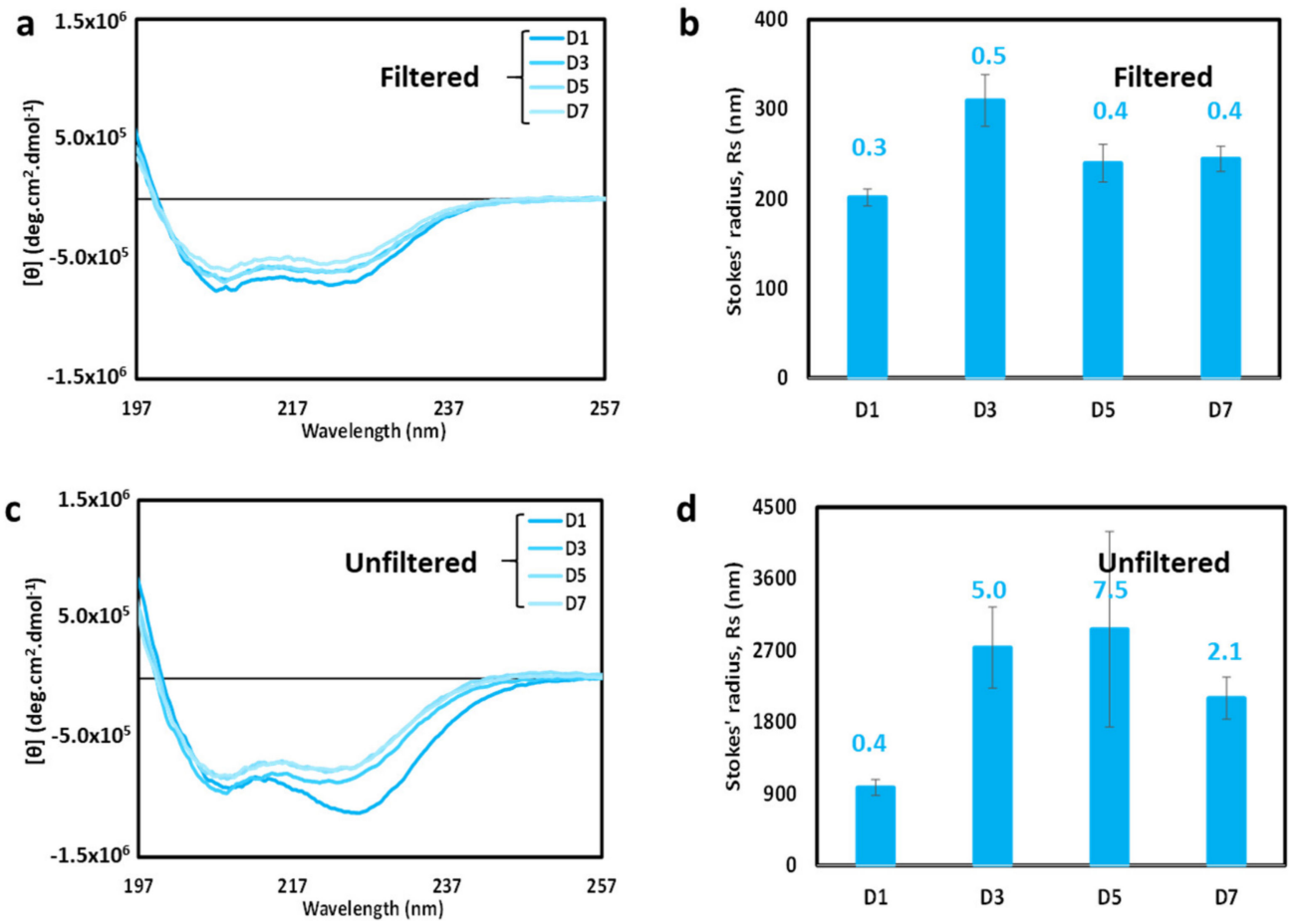

Figure 7. Time-dependence of cl-Par-4 in the presence of $50 \mathrm{mM} \mathrm{MgSO}_{4}$. (a) Overlay of CD spectra obtained over a seven-day time course. Sample was filtered on day 1 prior to the first spectrum. (b) DLS analysis of sample from panel (a). (c) Overlay of CD spectra obtained over a seven-day time course. Sample was NOT filtered. (d) DLS analysis of sample from panel (c). In panels (b) and (d), error bars represent the standard deviation in Stokes' radii from multiple runs, and the number above each bar represents the average polydispersity value for these runs.

\section{Discussion}

Full-length Par-4 (FL-Par-4) has been shown to be a largely intrinsically disordered protein (IDP) in vitro: CD spectroscopy and other techniques have previously been used to 
show that the C-terminal coiled-coil folds in FL-Par-4, while a large majority of the remainder of the protein maintains a disordered state under neutral conditions [34]. Caspase-3induced cleavage of FL-Par-4 to form the N-terminal 15 kilodalton PAF fragment and the C-terminal 25 kilodalton cl-Par-4 fragment is necessary for the migration of cl-Par- 4 to the nucleus, where it inhibits NF-kB-mediated cell survival pathways [13,14]. The PAF fragment has been shown to function as a decoy that protects FL-Par-4 from ubiquitin-mediated degradation [35].

We have previously shown that cl-Par-4 forms small, well-folded particles with approximately $80 \%$ helical content under either high sodium or low pH conditions $[23,24]$. There are differences, however. High sodium results in a tetramer conformation with a Stokes' radius of approximately $100 \mathrm{~nm}$, in which a significant portion of the helical content is not coiled coil. In contrast, acidic $\mathrm{pH}$ results in particles of a smaller size (approximately $50 \mathrm{~nm}$ Stokes' radius), suggestive of a dimer, which does display coiled-coil character. Here we have shown that potassium and sodium have similar effects on cl-Par- 4 structure (see Figure 2a). Thus, we can state that highly helical, significantly non-coiled particles, consistent with the Stokes' radius of a tetramer, are also formed at high potassium concentration. This is a potentially meaningful finding, since potassium levels are higher inside of cells (of the order of $100 \mathrm{mM}$ vs. $10 \mathrm{mM}$ inside vs. outside cells), and sodium levels are higher extracellularly (of the order of $10 \mathrm{mM}$ and $100 \mathrm{mM}$ inside vs. outside cells) [36,37]. This result suggests that cl-Par-4, which is found both intra- and extra-cellularly, may behave conformationally similarly inside and outside of the cell.

The amount of sodium or potassium necessary to induce the formation of these small helical particles appears to be higher than is typically encountered within either mammalian cellular or extra-cellular environments. In part for this reason, we investigated whether divalent cations could more efficiently induce this conformation. The results herein show that this is indeed the case, with $100 \mathrm{mM} \mathrm{MgSO}_{4}$ inducing the formation of relatively small, highly helical particles, at concentrations approximately five times lower than the required concentrations of sodium or potassium (see Figures $2 c$ and $3 a, b$ ). Together with previously published data identifying the conformation at high sodium concentration as a tetramer [24], this strongly suggests that tetramer is formed at the $100 \mathrm{mM} \mathrm{MgSO}_{4}$ concentration. The nearly identical results between $\mathrm{MgSO}_{4}$ and $\mathrm{MgCl}_{2}$ (see Figure 2d) also show that anion identity is far less important than cation identity for affecting cl-Par-4 conformation. The required magnesium concentration is still high relative to typical intra-cellular magnesium levels [36]. However, it has been reported that apoptosis is accompanied by alteration of cellular ionic conditions, including sodium, potassium, magnesium, chloride, calcium, and zinc, and changes in $\mathrm{pH}$ [36,38-41]. Thus, the combined effect of a number of factors should be considered, as they may conspire to affect the conformation of cl-Par- 4 and other cellular proteins under less extreme conditions than are required of any one of these factors. Furthermore, the techniques employed in these studies require high micromolar protein concentration. Since in vivo cl-Par-4 levels will not reach high micromolar concentrations, cl-Par-4 should be less prone to aggregate and may not require as high ionic strength in order to form small, well-folded particles in vivo.

In support of this view, the present analysis of CD data, DLS data including polydispersity values, sample filtration, and gel electrophoresis, has shown that a mixture of particle sizes are present under various conditions. For intermediate conditions, large particles can be removed by filtration or centrifugation, and sufficient small particles remain for secondary structure analysis. These particles, which are sufficiently small to survive filtration, apparently have a secondary structure that resembles that of the small particles found at high salt (see Figure 4b). Thus, cl-Par-4 clearly can form highly helical structures under both low and medium salt conditions. This is at least true for particles that are not highly aggregated. Secondary structure analysis of the larger aggregates is complicated by the effects of scattering and will be discussed in more detail elsewhere. 
As mentioned, approximately $80 \%$ helicity is observed in the small cl-Par-4 particles induced by sodium, potassium, or magnesium. The coiled-coil domain comprises only $38 \%$ of the cl-Par-4 sequence (see Figure 1a), thus additional helical regions are clearly present. Sequence analysis shows that the SAC domain, which comprises $28 \%$ of cl-Par-4, has the next highest order propensity (see Figure $1 b$ ). The linker domain has the highest disorder propensity. This strongly suggests that both the CC domain and at least a significant fraction of the SAC domain are helical in cl-Par-4 under these conditions. Previous biophysical analysis of FL-Par-4 provided no such evidence of folding of the SAC domain in the fulllength protein [34] and suggested that the helical content in FL-Par-4 is largely coiled-coil in nature. Thus, cleavage of Par- 4 by caspase- 3 may be important both for altering the SAC domain conformation, and for influencing the self-association characteristics, including helical coiling, of the cl-Par-4 fragment in comparison to FL-Par-4. These two effects may in fact be correlated. It remains to be seen how conformational and self-association changes upon caspase-induced cleavage may be related to controlling the role of Par-4 in apoptotic processes.

Author Contributions: Conceptualization, S.M.P.; methodology, K.K.R. and S.M.P.; formal analysis, K.K.R. and S.M.P.; investigation, K.K.R., K.P. and S.M.P.; resources, S.M.P.; writing-original draft preparation, K.K.R.; writing - review and editing, S.M.P. and K.K.R.; visualization, K.K.R. and S.M.P.; supervision, S.M.P.; project administration, S.M.P.; funding acquisition, S.M.P. All authors have read and agreed to the published version of the manuscript.

Funding: This research was supported by internal funds from Old Dominion University.

Institutional Review Board Statement: Not applicable.

Informed Consent Statement: Not applicable.

Acknowledgments: We wish to acknowledge Vivek Rangnekar for useful discussions regarding Par-4 function.

Conflicts of Interest: The authors declare no conflict of interest.

\section{References}

1. El-Guendy, N.; Zhao, Y.; Gurumurthy, S.; Burikhanov, R.; Rangnekar, V.M. Identification of a Unique Core Domain of Par-4 Sufficient for Selective Apoptosis Induction in Cancer Cells. Mol. Cell Biol. 2003, 23, 5516-5525. [CrossRef]

2. Rangnekar, V.M. Apoptosis by par-4 protein. In Advances in Cell Aging and Gerontology; Elsevier: Amsterdam, The Netherlands, 2001; pp. 215-236.

3. Boghaert, E.R.; Sells, S.F.; Walid, A.J.; Malone, P.; Williams, N.M.; Weinstein, M.H.; Strange, R.; Rangnekar, V.M. Immunohistochemical analysis of the proapoptotic protein Par-4 in normal rat tissues. Cell Growth Differ. 1997, 8, 881-890.

4. Gurumurthy, S.; Goswami, A.; Vasudevan, K.M.; Rangnekar, V.M. Phosphorylation of Par-4 by protein kinase A is critical for apoptosis. Mol. Cell Biol. 2005, 25, 1146-1161.

5. Rasool, R.U.; Nayak, D.; Chakraborty, S.; Katoch, A.; Faheem, M.M.; Amin, H.; Goswami, A. A journey beyond apoptosis: New enigma of controlling metastasis by pro-apoptotic Par-4. Clin. Exp. Metastasis 2016, 33, 757-764. [CrossRef] [PubMed]

6. Johnstone, R.W.; Tommerup, N.; Hansen, C.; Vissing, H.; Shi, Y. Mapping of the human PAWR (par-4) gene to chromosome 12 q21. Genomics 1998, 53, 241-243. [CrossRef] [PubMed]

7. Treude, F.; Kappes, F.; Fahrenkamp, D.; Muller-Newen, G.; Dajas-Bailador, F.; Kramer, O.H.; Luscher, B.; Hartkamp, J. Caspase-8mediated PAR-4 cleavage is required for TNFalpha-induced apoptosis. Oncotarget 2014, 5, 2988-2998. [CrossRef] [PubMed]

8. Thayyullathil, F.; Pallichankandy, S.; Rahman, A.; Kizhakkayil, J.; Chathoth, S.; Patel, M.; Galadari, S. Caspase-3 mediated release of SAC domain containing fragment from Par-4 is necessary for the sphingosine-induced apoptosis in Jurkat cells. J. Mol. Signal. 2013, 8, 2. [CrossRef] [PubMed]

9. El-Guendy, N.; Rangnekar, V.M. Apoptosis by Par-4 in cancer and neurodegenerative diseases. Exp. Cell Res. 2003, 283, 51-66. [CrossRef]

10. Burikhanov, R.; Zhao, Y.; Goswami, A.; Qiu, S.; Schwarze, S.R.; Rangnekar, V.M. The tumor suppressor Par-4 activates an extrinsic pathway for apoptosis. Cell 2009, 138, 377-388. [CrossRef] [PubMed]

11. Hebbar, N.; Wang, C.; Rangnekar, V.M. Mechanisms of apoptosis by the tumor suppressor Par-4. J. Cell Physiol. 2012, 227, 3715-3721. [CrossRef]

12. de Thonel, A.; Hazoumé, A.; Kochin, V.; Isoniemi, K.; Jego, G.; Fourmaux, E.; Hammann, A.; Mjahed, H.; Filhol, O.; Micheau, O.; et al. Regulation of the proapoptotic functions of prostate apoptosis response-4 (Par-4) by casein kinase 2 in prostate cancer cells. Cell Death Dis. 2014, 5, e1016. [CrossRef] 
13. Chaudhry, P.; Singh, M.; Parent, S.; Asselin, E. Prostate apoptosis response 4 (Par-4), a novel substrate of caspase-3 during apoptosis activation. Mol. Cell Biol. 2012, 32, 826-839. [CrossRef] [PubMed]

14. Diaz-Meco, M.T.; Lallena, M.J.; Monjas, A.; Frutos, S.; Moscat, J. Inactivation of the inhibitory kappaB protein kinase/nuclear factor kappaB pathway by Par-4 expression potentiates tumor necrosis factor alpha-induced apoptosis. J. Biol. Chem. 1999, 274, 19606-19612. [CrossRef] [PubMed]

15. Shrestha-Bhattarai, T.; Rangnekar, V.M. Cancer-selective apoptotic effects of extracellular and intracellular Par-4. Oncogene 2010, 29, 3873-3880. [CrossRef] [PubMed]

16. Uversky, V.N. Intrinsically Disordered Proteins and Their "Mysterious" (Meta)Physics. Front. Phys. 2019, 7, 10. [CrossRef]

17. Wright, P.E.; Dyson, H.J. Intrinsically disordered proteins in cellular signalling and regulation. Nat. Rev. Mol. Cell Biol. 2015, 16, 18-29. [CrossRef]

18. Dyson, H.J.; Wright, P.E. Intrinsically unstructured proteins and their functions. Nat. Rev. Mol. Cell Biol. 2005, 6, 197-208. [CrossRef]

19. Uversky, V.N.; Gillespie, J.R.; Fink, A.L. Why are "natively unfolded" proteins unstructured under physiologic conditions? Proteins 2000, 41, 415-427. [CrossRef]

20. Uversky, V.N. What does it mean to be natively unfolded? Eur. J. Biochem. 2002, 269, 2-12. [CrossRef]

21. Uversky, V.N. Intrinsically disordered proteins and their environment: Effects of strong denaturants, temperature, $\mathrm{pH}$, counter ions, membranes, binding partners, osmolytes, and macromolecular crowding. Protein J. 2009, 28, 305-325. [CrossRef]

22. Wicky, B.I.M.; Shammas, S.L.; Clarke, J. Affinity of IDPs to their targets is modulated by ion-specific changes in kinetics and residual structure. Proc. Natl. Acad. Sci. USA. 2017, 114, 9882-9887. [CrossRef] [PubMed]

23. Clark, A.M.; Ponniah, K.; Warden, M.S.; Raitt, E.M.; Yawn, A.C.; Pascal, S.M. pH-Induced Folding of the Caspase-Cleaved Par-4 Tumor Suppressor: Evidence of Structure Outside of the Coiled Coil Domain. Biomolecules 2018, 8, 4060-4073. [CrossRef] [PubMed]

24. Clark, A.M.; Ponniah, K.; Warden, M.S.; Raitt, E.M.; Smith, B.G.; Pascal, S.M. Tetramer formation by the caspase-activated fragment of the Par-4 tumor suppressor. FEBS J. 2019, 286, 4060-4073. [CrossRef]

25. Alexandrov, A.; Dutta, K.; Pascal, S.M. MBP fusion protein with a viral protease cleavage site: One-step cleavage/purification of insoluble proteins. Biotechniques 2001, 30, 1194-1198. [CrossRef]

26. Whitmore, L.; Wallace, B.A. DICHROWEB, an online server for protein secondary structure analyses from circular dichroism spectroscopic data. Nucleic Acids Res. 2004, 32, W668-W673. [CrossRef] [PubMed]

27. Ward, J.J.; McGuffin, L.J.; Bryson, K.; Buxton, B.F.; Jones, D.T. The DISOPRED server for the prediction of protein disorder. Bioinformatics 2004, 20, 2138-2139. [CrossRef]

28. Jones, D.T.; Cozzetto, D. DISOPRED3: Precise disordered region predictions with annotated protein-binding activity. Bioinformatics 2014, 31, 857-863. [CrossRef]

29. Wuo, M.G.; Mahon, A.B.; Arora, P.S. An Effective Strategy for Stabilizing Minimal Coiled Coil Mimetics. J. Am. Chem. Soc. 2015, 137, 11618-11621. [CrossRef]

30. Kallenbach, N.R.; Lyu, P.; Zhou, H. CD Spectroscopy and the Helix-Coil Transition in Peptides and Polypeptides. In Circular Dichroism and the Conformational Analysis of Biomolecules; Fasman, G.D., Ed.; Springer: Boston, MA, USA, 1996; pp. $201-259$.

31. Cooper, T.M.; Woody, R.W. The effect of conformation on the CD of interacting helices: A theoretical study of tropomyosin. Biopolymers 1990, 30, 657-676. [CrossRef]

32. Wallace, B.A.; Mao, D. Circular dichroism analyses of membrane proteins: An examination of differential light scattering and absorption flattening effects in large membrane vesicles and membrane sheets. Anal. Biochem. 1984, 142, 317-328. [CrossRef]

33. Kelly, S.M.; Jess, T.J.; Price, N.C. How to study proteins by circular dichroism. Biochim. Biophys. Acta Proteins Proteom. 2005, 1751, 119-139. [CrossRef] [PubMed]

34. Libich, D.S.; Schwalbe, M.; Kate, S.; Venugopal, H.; Claridge, J.K.; Edwards, P.J.B.; Dutta, K.; Pascal, S.M. Intrinsic disorder and coiled-coil formation in prostate apoptosis response factor 4. FEBS J. 2009, 276, 3710-3728. [CrossRef] [PubMed]

35. Hebbar, N.; Burikhanov, R.; Shukla, N.; Qiu, S.; Zhao, Y.; Elenitoba-Johnson, K.S.J.; Rangnekar, V.M. A Naturally Generated Decoy of the Prostate Apoptosis Response-4 Protein Overcomes Therapy Resistance in Tumors. Cancer Res. 2017, 77, 4039-4050. [CrossRef]

36. Ishaque, A.; Al-Rubeai, M. Role of $\mathrm{Ca} 2+, \mathrm{Mg} 2+$ and $\mathrm{K}+$ ions in determining apoptosis and extent of suppression afforded by bcl-2 during hybridoma cell culture. Apoptosis 1999, 4, 335-355. [CrossRef] [PubMed]

37. Melkikh, A.V.; Sutormina, M.I. Model of active transport of ions in cardiac cell. J. Theor. Biol. 2008, 252, 247-254. [CrossRef]

38. Pilchova, I.; Klacanova, K.; Tatarkova, Z.; Kaplan, P.; Racay, P. The Involvement of $\operatorname{Mg}(2+)$ in Regulation of Cellular and Mitochondrial Functions. Oxid. Med. Cell Longev. 2017, 2017, 6797460. [CrossRef]

39. Franklin, R.B.; Costello, L.C. The important role of the apoptotic effects of zinc in the development of cancers. J. Cell Biochem. 2009, 106, 750-757. [CrossRef]

40. Bortner, C.D.; Cidlowski, J.A. Ion channels and apoptosis in cancer. Philos. Trans. R Soc. B 2014, 369, 20130104. [CrossRef]

41. Lang, F.; Föller, M.; Lang, K.S.; Lang, P.A.; Ritter, M.; Gulbins, E.; Vereninov, A.; Huber, S.M. Ion Channels in Cell Proliferation and Apoptotic Cell Death. J. Membr. Biol. 2005, 205, 147-157. [CrossRef] 